Article

\title{
Effect of Porosity on the Thick Electrodes for High Energy Density Lithium Ion Batteries for Stationary Applications
}

\author{
Madhav Singh ${ }^{1, *}$, Jörg Kaiser ${ }^{2,+}$ and Horst Hahn ${ }^{1,3,+}$ \\ 1 Institute of Nanotechnology, Karlsruhe Institute of Technology (KIT), Hermann-von-Helmholtz-Platz 1, \\ 76344 Eggenstein-Leopoldshafen, Germany; horst.hahn@kit.edu \\ 2 Project Competence-E, Karlsruhe Institute of Technology (KIT), Hermann-von-Helmholtz-Platz 1, \\ 76344 Eggenstein-Leopoldshafen, Germany; jkaiser.ulm@web.de \\ 3 Helmholtz Institute Ulm for Electrochemical Energy Storage (HIU), Albert-Einstein-Allee 11, \\ 89081 Ulm, Germany \\ * Correspondence: madhav@iitdalumni.com; Tel.: +49-721-60826351 \\ + These authors contributed equally to this work.
}

Academic Editor: Maciej Swierczynski

Received: 21 September 2016; Accepted: 11 November 2016; Published: 22 November 2016

\begin{abstract}
A series of 250-350 $\mu \mathrm{m}$-thick single-sided lithium ion cell graphite anodes and lithium nickel manganese cobalt oxide (NMC) cathodes with constant area weight, but varying porosity were prepared. Over this wide thickness range, micron-sized carbon fibers were used to stabilize the electrode structure and to improve electrode kinetics. By choosing the proper porosities for the anode and cathode, kinetic limitations and aging losses during cell cycling could be minimized and energy density improved. The cell (C38\%-A48\%) exhibits the highest energy density, $441 \mathrm{Wh} / \mathrm{L}$ at the $\mathrm{C} / 10$ rate, upon cycling at elevated temperature and different C-rates. The cell (C38\%-A48\%) showed $9 \%$ higher gravimetric energy density at C/10 in comparison to the cell with as-coated electrodes.
\end{abstract}

Keywords: lithium ion battery; thick electrodes; porosity; carbon fibers

\section{Introduction}

One of the most decisive parameters of lithium ion cells is their energy density. It is constantly improved by a plurality of measures, which can be grouped into measures that address the increase of the energy density of the active materials (e.g., higher coulometric density for anodes or higher voltages for cathodes) or to minimize the portion of inactive materials, such as separator thickness, higher compression of electrodes, thinner aluminum and copper substrate foils and smaller void volume inside the casing of the cell.

We have recently published a study [1], where we showed that an increase of the electrode thickness to up to $320 \mu \mathrm{m}$ and thereby scaling up the ratio of active material to aluminum and copper foil can be used to increase the energy density of lithium ion cells by $19 \%$. However, at these thicknesses, electron transport from the substrate foil to the active material particles in an electrode layer, as well as lithium ion transport in the electrolyte phase in the pores of an electrode layer become increasingly critical. We had described how charging a thick graphite anode can lead to circumstances where graphite particles close to the separator experience conditions that favor undesirable lithium plating.

In this work, we present a systematic study of thick graphite anodes and lithium nickel manganese cobalt oxide (NMC) cathodes, where the area weight is kept constant (see Section 2), but where porosity and thickness are varied between $38 \%-58 \%$ and $250-350 \mu \mathrm{m}$ respectively. Conventional electrode recipes with polyvinylidene fluoride (PVDF) binder and graphite and carbon black conducting aids 
would not give mechanically-stable electrode coatings, which is why we added micrometer-sized carbon fibers [2,3]. These should act as (a) medium range electron conductors and distributors inside the layer and (b) porosity enhancers, given their linear shape, which is embedded in a matrix of spherical particles. Carbon fibers in lithium ion electrodes have been claimed to be beneficial for cell performance before by companies, such as LG Chemical (Newport Beach, CA, USA) [4] or Showa Denko (Tokyo, Japan) [5].

\section{Experimental Section}

\subsection{Electrodes' Preparation}

Pairs of energy-optimized anodes and cathodes based on synthetic graphite and NMC (111) as active materials were studied; an active material combination that is commonly used in lithium ion cells for automotive or stationary applications. Nine batches of single-sided thick electrodes with different porosities were prepared and characterized to optimize the porosity in terms of volumetric energy density (Wh/L).

Commercially available battery-grade cathode material $\mathrm{LiNi}_{1 / 3} \mathrm{Mn}_{1 / 3} \mathrm{Co}_{1 / 3} \mathrm{O}_{2}(\mathrm{NMC}, \mathrm{BASF}$, Hannover, Germany) and anode material graphite SMG-A (Hitachi, Tokyo, Japan) were used as the active materials. Solef 5130 PVDF (Solvay, Bollate, Italy) was used as a binder, while Super C65 carbon black, KS6L graphite (Imerys, Bodio, Switzerland, formerly Timcal) and milled carbon fibers (SIGRAFIL, C M150-4.0/240-UN, SGL Group, Meitingen, Germany) were used as conductive agents. The carbon fibers have a mean fiber length of $\sim 150 \mu \mathrm{m}$, a filament diameter of $7 \mu \mathrm{m}$ and fiber density of $1.8 \mathrm{~g} / \mathrm{cm}^{3}$. There was no pre-treatment performed on the carbon fibers before mixing with other materials. All materials and substrates were used as delivered. PVDF was dissolved in $\mathrm{N}$-methyl-pyrrolidone (NMP) at $60^{\circ} \mathrm{C}$ under stirring.

The cathode slurry was prepared by mixing NMC (90 wt\%), Super C65 carbon black ( $3 \mathrm{wt} \%)$, KS6L graphite ( $3 \mathrm{wt} \%)$, carbon fibers (1 $\mathrm{wt} \%$ ) and PVDF (3 $\mathrm{wt} \%)$, dissolved in NMP. The anode slurry was prepared by mixing graphite (92 $\mathrm{wt} \%)$, Super C65 carbon black (3 $\mathrm{wt} \%)$, carbon fibers $(1 \mathrm{wt} \%)$ and PVDF (4 wt\%), dissolved in NMP. These mixtures were further stirred and homogenized with a dispersing system (Dissolver Dispermat CA40, VMA-Getzmann GmbH, Reichshof, Germany) for approximately $2 \mathrm{~h}$. Finally, the slurries were deaerated under vacuum for $1 \mathrm{~h}$ to remove the bubbles. The cathode slurry was then cast on aluminum foil (thickness: $20 \mu \mathrm{m}$ ), and the anode slurry was cast on copper foil (thickness: $10 \mu \mathrm{m}$ ). Anodes and cathodes of different thicknesses were prepared by varying the doctor blade height. The coated electrodes were dried in an oven at $120^{\circ} \mathrm{C}$ in an ambient atmosphere for $30 \mathrm{~min}$.

A calendering roll pressure was applied to reduce $5 \%$ and $10 \%$ on the cathode side and $5 \%, 10 \%$, $15 \%$ and $20 \%$ on the anode side of the original thickness of the dried slurry film, so that different porosities could be maintained in the electrodes. These values are somewhat higher than the ca. $30 \%$ porosity typically found in commercial electrodes. However, to minimize lithium ion transport losses in the electrolyte phase rather than improve electric conductivity and volumetric energy density of the layer, we opted for higher porosities.

The average mass loadings of the cathode electrode with a $300-\mu \mathrm{m}$ thickness and anode electrode with a $350-\mu \mathrm{m}$ thickness (as-coated, exclusive of current collector foil) were $\sim 71 \mathrm{mg} / \mathrm{cm}^{2}$ and $\sim 41 \mathrm{mg} / \mathrm{cm}^{2}$, respectively.

Cathode: NMC (81\%), carbon black (6.7\%), graphite (5.3\%), PVDF (7\%) and carbon fiber $(2.3 \%)$ in volume\%; anode: graphite $(91.4 \%)$, carbon black $(2.6 \%), \operatorname{PVDF}(5 \%)$ and carbon fiber $(1.24 \%)$ in volume $\%$.

\subsection{Cell Preparation and Characterization}

Pouch bag cells with one anode and cathode sheet each were assembled in a dry room with dew points below $-70{ }^{\circ} \mathrm{C}$. The active areas of the cathodes and anodes sheets were $5 \times 5 \mathrm{~cm}^{2}$ and 
$5.4 \times 5.4 \mathrm{~cm}^{2}$, respectively. It should be noted that during cutting and drying, both electrodes showed good mechanical integrity and stable edges. Electrodes were dried at $130{ }^{\circ} \mathrm{C}$ under vacuum overnight. Nickel and aluminum cell terminals were welded on anode and cathode electrodes by ultrasound, respectively. The electrolyte used in all cases was LP30 (BASF SE, Ludwigshafen, Germany) with vinylene carbonate (VC) (11.5 wt\% $\mathrm{LiPF}_{6}, 42.8 \mathrm{wt} \%$ ethylene carbonate (EC) , $42.8 \mathrm{wt} \%$ dimethyl carbonate (DMC) , $2.9 \mathrm{wt} \% \mathrm{VC}, \mathrm{BASF})$.

The lithium ion full cells were cycled galvanostatically at various currents in the voltage range of 3.0-4.2 $\mathrm{V}$ and potentiostatically at $4.2 \mathrm{~V}$ for $30 \mathrm{~min}$ using an Arbin BT 2000 battery tester (Arbin Instruments, College Station, TX, USA) and a Binder temperature chamber (BINDER GmbH, Tuttlingen, Germany) at temperatures of $23^{\circ} \mathrm{C}, 40^{\circ} \mathrm{C}$ and $10^{\circ} \mathrm{C}$. The Gamry potentiostat (Interface 1000) (Gamry Instruments, Warminster, PA, USA) was used to measure the impedance of the Li-ion full cells. The impedance was measured at $3.7 \mathrm{~V}$ in the frequency range of $100 \mathrm{kHz}-1 \mathrm{mHz}$ at different temperatures $\left(23^{\circ} \mathrm{C}, 40^{\circ} \mathrm{C}\right.$ and $10^{\circ} \mathrm{C}$ ). Scanning electron microscopy (Leo 1530 microscope, Carl Zeiss Microscopy $\mathrm{GmbH}$, Oberkochen, Germany) was used to view the difference between as-coated and calendered electrodes. The cell index (full cell names) with anode and cathode porosities is given in Table 1.

Table 1. Cell index with anode and cathode porosities.

\begin{tabular}{ccc}
\hline Cell Code & Cathode (Porosity\%) & Anode (Porosity\%) \\
\hline Cell A & $44 \%$ & $58 \%$ \\
Cell B & $41 \%$ & $56 \%$ \\
Cell C & $41 \%$ & $54 \%$ \\
Cell D & $41 \%$ & $51 \%$ \\
Cell E & $41 \%$ & $48 \%$ \\
Cell F & $38 \%$ & $56 \%$ \\
Cell G & $38 \%$ & $54 \%$ \\
Cell H & $38 \%$ & $51 \%$ \\
Cell I & $38 \%$ & $48 \%$ \\
\hline
\end{tabular}

\section{Results and Discussion}

Figure 1 shows the morphological images (as-coated, calendered and high magnification calendered) of the graphite anode and NMC cathode. Electrodes show evenly-distributed active material particles and pores on the electrode surface. The scanning electron microscope (SEM) images show a uniform, crack-free and stable coating throughout the electrode surface. It would be worth mentioning here that even with the low binder content, $4 \mathrm{wt} \%$ in anode and $3 \mathrm{wt} \%$ in cathode electrodes and an additional $1 \mathrm{wt} \%$ of carbon fibers each, no delamination and loose particles were found in the cutting process during the cell assembly.

High magnification SEM images of both electrodes show that carbon fibers, which make up $2.2 \mathrm{vol} \%$ of the solid material in the cathode and $1.2 \mathrm{vol} \%$ in the anode, are scattered, not agglomerated and well embedded in the layers. In this way, they provide paths for better long-range conductivity in comparison to conductivity among the particle to particle contact (Figure 1c,f). In addition, the porosity in the direct vicinity of a carbon fiber is increased, and the dense sphere packing of the active material particles softened up. This way, carbon fibers act three-fold as improvers of the mechanical stability of a electrode layer, the long-range electric conductivity and the long-range conductivity of ions in the liquid filled pores. Admittedly, the latter two should be the most effective in the direction of current flow, which is perpendicular to the plain of the electrodes. However, such a forced orientation of the fibers could not be achieved with the standard slurry coating and drying method used here during electrode preparation. 

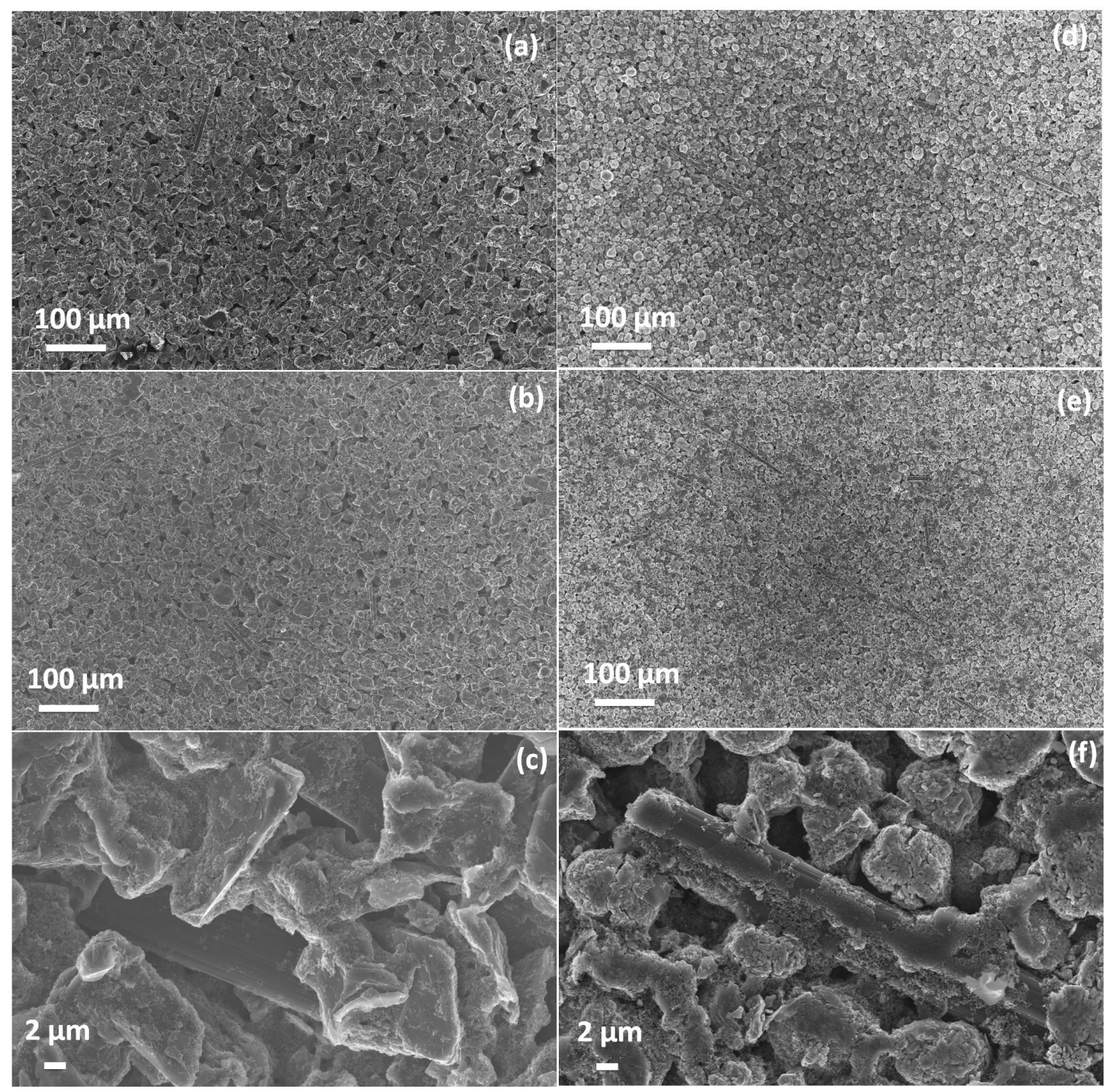

Figure 1. Scanning electron microscope (SEM) images of the thick electrodes. (left) Graphite anode: (a) as-coated (350 $\mu \mathrm{m}$, porosity $58 \%$ ); (b) calendered ( $280 \mu \mathrm{m}$, porosity $48 \%$ ); and (c) high magnification (280 $\mu \mathrm{m}$, porosity 48\%). (right) Lithium nickel manganese cobalt oxide (NMC) cathode: (d) as-coated (300 $\mu \mathrm{m}$, porosity $44 \%)$; (e) calendered $(250 \mu \mathrm{m}$, porosity $38 \%)$; and (f) high magnification (250 $\mu \mathrm{m}$, porosity $38 \%$ ).

To achieve the optimum utilization and electrochemical performance of the active material in the thick electrodes, the appropriate porosity should be selected. To understand the effect of the porosity, the full cells were stopped at $3.7 \mathrm{~V}$ and paused for $30 \mathrm{~min}$, before a discharge current pulse at $\mathrm{C} / 2$ rate for $20 \mathrm{~s}$ was applied. Figure 2 shows the corresponding voltage profiles, which were recorded directly after formation (Figure 2a) and after 90 cycles (Figure 2b). The full cell Cell A (C44\%-A58\%) with as-coated electrodes showed the largest voltage drop ( $205 \mathrm{mV}$, after formation cycles) in comparison to the other cells. This indicates that the cell would reach the cut-off voltages faster, and therefore, the whole active material cannot be utilized. It was observed that the voltage drop is decreased as the porosity decreases [6]. The cells with porosity of $38 \%$ on the cathode side showed the minimum voltage drop $(\sim 56 \mathrm{mV})$ after the formation cycles.

A more significant voltage drop could be seen after 90 cycles. The voltage drops get smaller and smaller as the porosities are decreased. The full cells showed voltage drops of $262 \mathrm{mV}, 197 \mathrm{mV}$, $181 \mathrm{mV}, 115 \mathrm{mV}, 137 \mathrm{mV}, 103 \mathrm{mV}, 98 \mathrm{mV}, 77 \mathrm{mV}$ and $74 \mathrm{mV}$ with the cells Cell A(C44\%-A58\%), Cell B (C41\%-A56\%), Cell C (C41\%-A54\%), Cell D (C41\%-A51\%), Cell E (C41\%-A48\%), Cell F (C38\%-A56\%), 
Cell G (C38\%-A54\%), Cell H (C38\%-A51\%) and Cell I (C38\%-A48\%), respectively. The cells with the minimum maintained porosities, $38 \%$ on the cathode side and $48 \%$ and $51 \%$ on the anode side, showed the lowest potential drop.

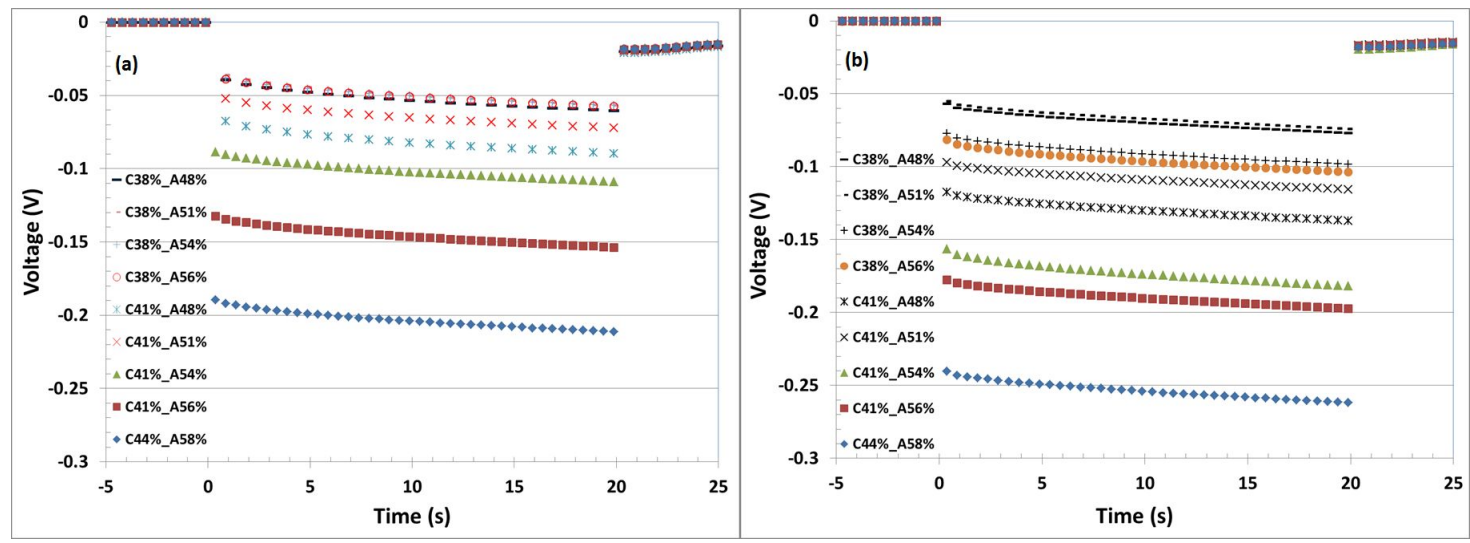

Figure 2. $U(t)$ diagrams of discharge pulses at $3.7 \mathrm{~V}$ and at $\mathrm{C} / 2$ for $20 \mathrm{~s}$ : (a) after formation cycles; and (b) after 90 cycles.

All voltage transients in Figure 2 are of similar shape and aligned in parallel. They differ only by the initial voltage offset at the beginning of the discharge pulse. This means that the cells vary primarily by internal ohmic resistances, whereas the mass transport of lithium ions in the liquid phase influenced by the pore structure does not have an effect (at C/2 and 20-s pulse duration). Given the dependency on calendering force, we believe that these cells are limited by the particle to particle contact resistance for electron transport. The column plot of Figure 3 gives a clearer view of the relation of anode and cathode porosities on the DC pulse resistance. Right after the formation and at the beginning of life, Cells F, G, H and I have the same DC resistances, which are governed by cathode porosity, but not anode porosity. After 90 cycles, Cells $\mathrm{H}$ and I show the smallest increase of DC resistance by $29 \%$, whereas the resistances of the other calendered cells increased by $29 \%-82 \%$.

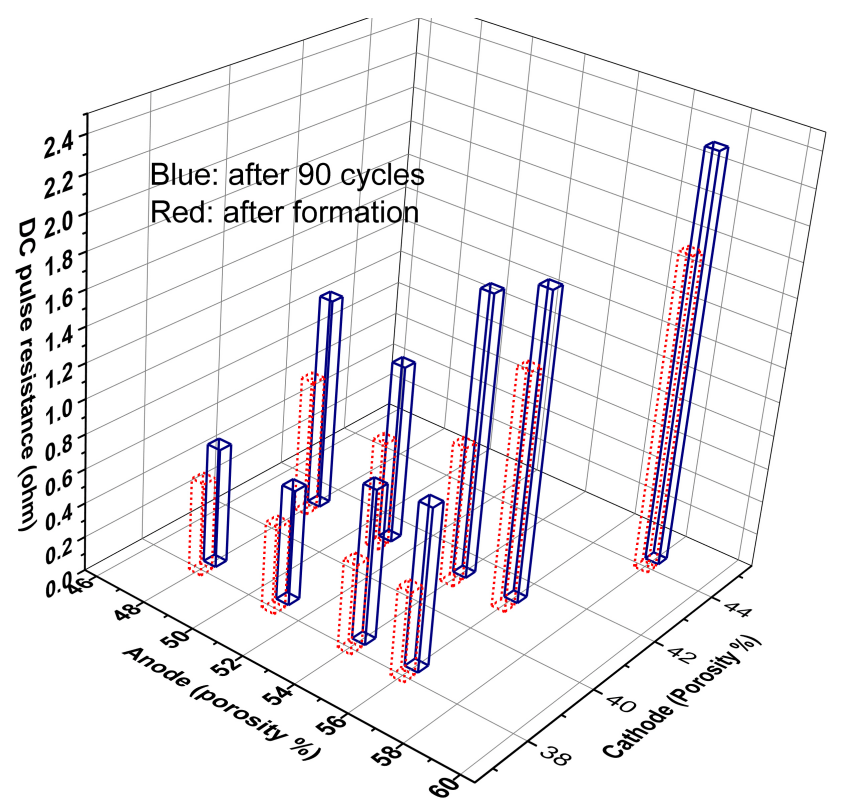

Figure 3. DC resistances of full cells obtained from Figure 2 plotted vs. anode and cathode porosity. Cell A with uncalendered electrodes and $44 \%$ cathode porosity and $58 \%$ anode porosity has the highest DC resistance. 
The gravimetric energy density values in $\mathrm{Wh} / \mathrm{kg}$ obtained from the full cells containing thick electrodes with different porosities at different C-rates are compared in Figure 4. The weight of the single-sided electrodes with the substrate foils, the weight of the separator and electrolyte are used to calculate the energy density. The pouch foil and current tabs are not included in the calculation.

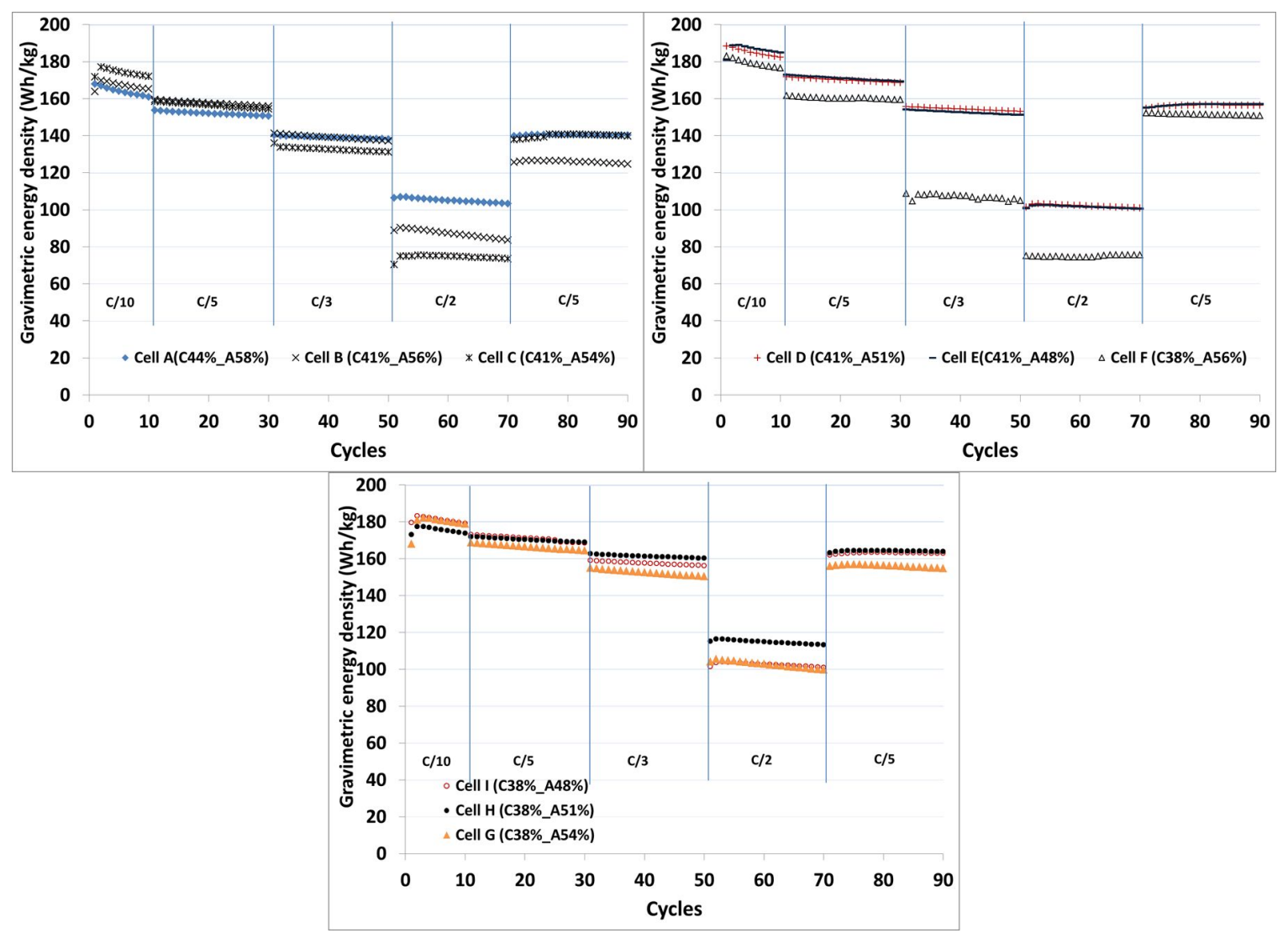

Figure 4. Comparison of the gravimetric energy density $(\mathrm{Wh} / \mathrm{kg}$ ) values obtained from the graphite-NMC-based full cells at different C-rates.

An initial energy density of $167 \mathrm{Wh} / \mathrm{kg}$ was observed for the full cell with as-coated electrodes in Cell A (C44\%-A58\%). An increase in the energy density from $167 \mathrm{Wh} / \mathrm{kg}(100 \%)$ to $170 \mathrm{Wh} / \mathrm{kg}(102 \%)$, $177 \mathrm{Wh} / \mathrm{kg}(106 \%), 188 \mathrm{Wh} / \mathrm{kg}(113 \%), 189 \mathrm{Wh} / \mathrm{kg}(113 \%), 182 \mathrm{Wh} / \mathrm{kg}(109 \%), 181 \mathrm{Wh} / \mathrm{kg}(109 \%)$, $177 \mathrm{Wh} / \mathrm{kg}(106 \%)$ and $183 \mathrm{Wh} / \mathrm{kg}(109 \%)$ is obtained at C/10 rate when the porosity is decreased from Cell A (C44\%-A58\%) to Cell B (C41\%-A56\%), Cell C (C41\%-A54\%), Cell D (C41\%-A51\%), Cell E (C41\%-A48\%), Cell F (C38\%-A56\%), Cell G (C38\%-A54\%), Cell H (C38\%-A51\%) and Cell I (C38\%-A48\%), respectively. A significant improvement in the energy density could be observed when the cathodes have $41 \%$ porosity, but the energy density is reduced as the porosity is decreased to $38 \%$ at the $\mathrm{C} / 10$ rate.

The energy density values provide the information about the optimal porosity when the cells are cycled at different $\mathrm{C}$-rates. Cells $\mathrm{H}$ and I show the highest energy density in comparison to other cells at the $\mathrm{C}$-rates higher than $\mathrm{C} / 10$. Cell $\mathrm{H}$ showed significantly less energy density losses of $3 \%$, $8 \%$ and $34 \%$ upon cycling at $C / 5, C / 3$ and $C / 2$, respectively. At C-rates higher than $C / 5$, Cell I (C38\%-A48\%) showed slightly lower energy density in comparison to $\mathrm{Cell} \mathrm{H}$ (C38\%-A51\%) which is due to kinetic limitations. Kinetic limitations are negligible at the $\mathrm{C} / 10$ rate. As the $\mathrm{C}$-rate increases, the kinetic limitations also increase. The cell with $48 \%$ porosity on the anode side contains slightly less electrolyte than the cell with $51 \%$ porosity on the anode side. The porosity of the electrodes in the Cell I (C38\%-A48\%) could be further reduced at the separator electrode interface during cycling, because the intercalation-deintercalation reaction rate is maximum at the electrode separator interface. 
Other cells with higher porosity are quite unstable at higher C-rates. After applying cycles at $\mathrm{C} / 2$, Cell H (C38\%-A51\%) and Cell I (C38\%-A48\%) are restored back to their initial energy density values after 70 cycles.

From the results, it is clear that the porosity $>51 \%$ on the anode side and that $>40 \%$ on the cathode side do not enhance the electrochemical performance, which might be due to the decrease in mechanical properties during the cycling. It could be mentioned here that the variation in the energy density values could be due to the different electrode structures, mechanical strength and particle to particle contact throughout the electrode surface [7]. Besides, the electrode-electrolyte interface area is varied by varying the porosity of the electrodes, and accordingly, the transport resistance is also varied [8]. The variation in the resistance with respect to the change in porosity could be seen during fast discharge test measurements.

In order to study the effect of porosity on the cell impedance, the electrochemical impedance spectroscopy (EIS) measurements are done at $50 \%$ state of charge (SOC) at $23{ }^{\circ} \mathrm{C}, 40{ }^{\circ} \mathrm{C}$ and $10^{\circ} \mathrm{C}$. Figure 5 displays the Nyquist plots of the EIS obtained from Li-ion cells, containing NMC cathodes with $38 \%$ porosity and graphite anodes with $48 \%, 51 \%$ and $54 \%$ porosities, after cycling at temperatures of $23{ }^{\circ} \mathrm{C}, 40{ }^{\circ} \mathrm{C}$ and $10{ }^{\circ} \mathrm{C}$. The Nyquist plots consist of two semicircles in the high to medium frequency ranges, as well as a straight line in the low frequency range. The latter reflects the diffusion process represented by the well-known $45^{\circ}$ slope Warburg diffusion. The semicircles provide the information about lithium migration through surface films on the electrodes and charge transfer processes within the electrodes. The high frequency intercept at $Z_{r}$-axis corresponds to the electronic resistance; the first semicircle in the high frequency range corresponds to the surface film or passivating film resistance; and the second semicircle in the medium frequency range represents the charge transfer resistance [9].

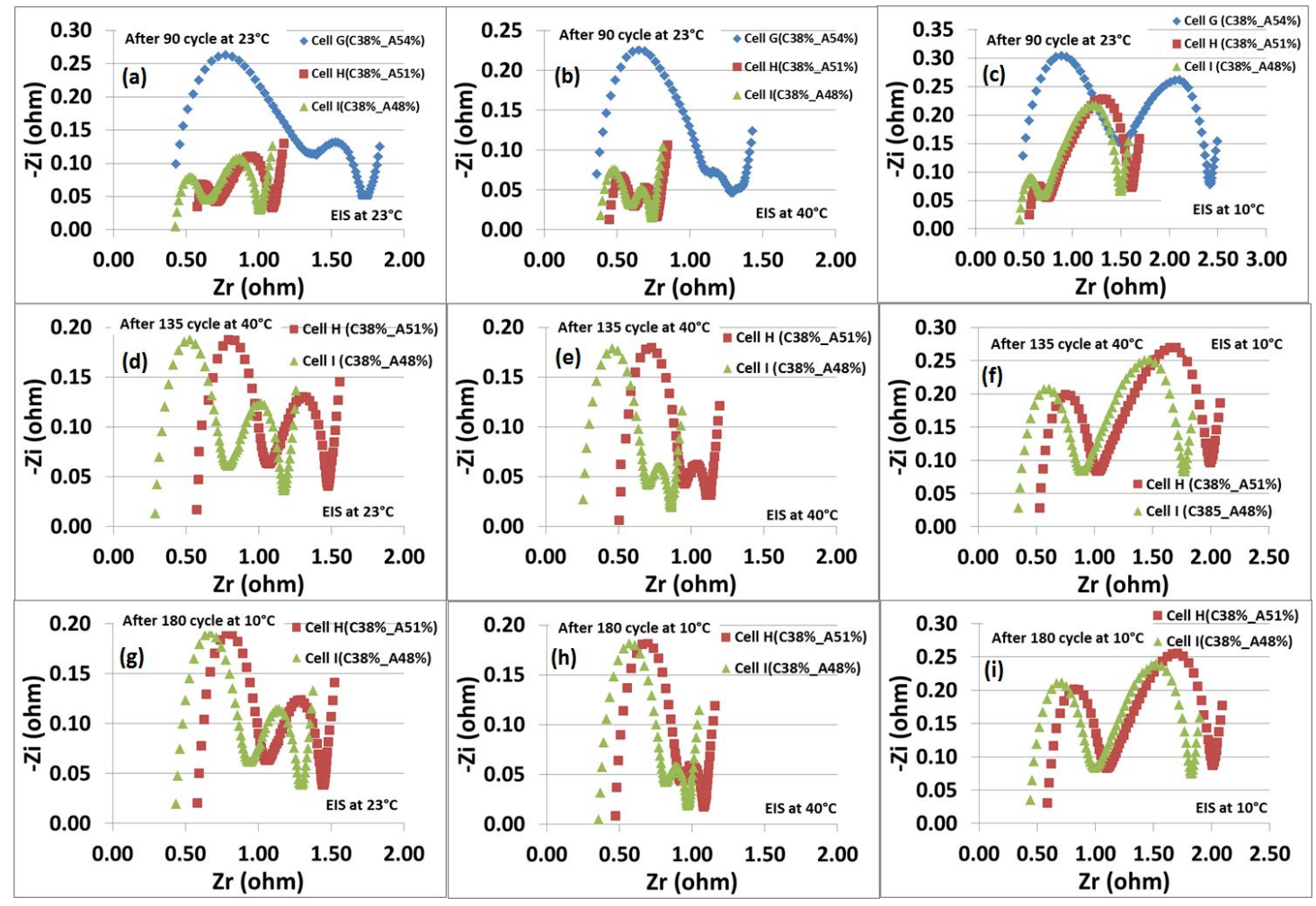

Figure 5. Impedance spectra of Li-ion full cells containing electrodes with different porosities: (a-c) electrochemical impedance spectroscopy (EIS) measurement at $23{ }^{\circ} \mathrm{C}, 40^{\circ} \mathrm{C}$ and $10{ }^{\circ} \mathrm{C}$ after 90 cycles cycled at $23^{\circ} \mathrm{C}$, respectively; (d-f) EIS measurement at $23^{\circ} \mathrm{C}, 40^{\circ} \mathrm{C}$ and $10^{\circ} \mathrm{C}$ after 135 cycles cycled at $40^{\circ} \mathrm{C}$, respectively; (g-i) EIS measurement at $23^{\circ} \mathrm{C}, 40^{\circ} \mathrm{C}$ and $10^{\circ} \mathrm{C}$ after 180 cycles cycled at $10^{\circ} \mathrm{C}$, respectively. 
There is no significant difference observed in the electronic resistances $\left(R_{e}\right)$, but Cell I (C38\%-A48\%) has slightly lower $R_{e}$, which indicates that a good electric conductive network has formed in the electrode. As can be seen from Figure 5, the Li-ion full Cell G (C38\%-A54\%) shows the $R_{s}, 764 \mathrm{~m} \Omega$, and $R_{c t}, 711 \mathrm{~m} \Omega$, after 90 cycles cycled at $23{ }^{\circ} \mathrm{C}$. $R_{s}$ is decreased by over $78 \%(169 \mathrm{~m} \Omega)$ and $74 \%$ $(200 \mathrm{~m} \Omega)$, and $R_{c t}$ decreased by over $45 \%(388 \mathrm{~m} \Omega)$ and $47 \%(373 \mathrm{~m} \Omega)$ with Cell $\mathrm{H}(\mathrm{C} 38 \%-\mathrm{A} 51 \%)$ and Cell I (C38\%-A48\%), respectively. A reduction in the resistances could be due to an improved surface particle, as well as particle to particle contact among the active material particles upon reducing the porosity $[10,11]$.

An increase in the size of high frequency semicircles was seen when the cells Cell $\mathrm{H}$ (C38\%-A51\%) and Cell I (C38\%-A48\%) were cycled for the next 45 cycles at $40{ }^{\circ} \mathrm{C}$, while no significant change was observed when the cells were cycled for the next 45 cycles at $10{ }^{\circ} \mathrm{C}$, indicating that a stable solid-electrolyte interphase (SEI) has formed on the graphite particles. The sizes of the medium frequency semicircles are changing gradually upon cycling.

Figure 6 shows a comparison study of the observed resistance values for $\mathrm{Li}$-ion cells consisting of thick electrodes with different porosities. The EIS spectrum and resistance values indicate that the cell impedance has been increased over a number of cycles which could be correlated with the mechanical stability, passivating film and Li-ion movement in the Li-ion cells $[9,11]$.

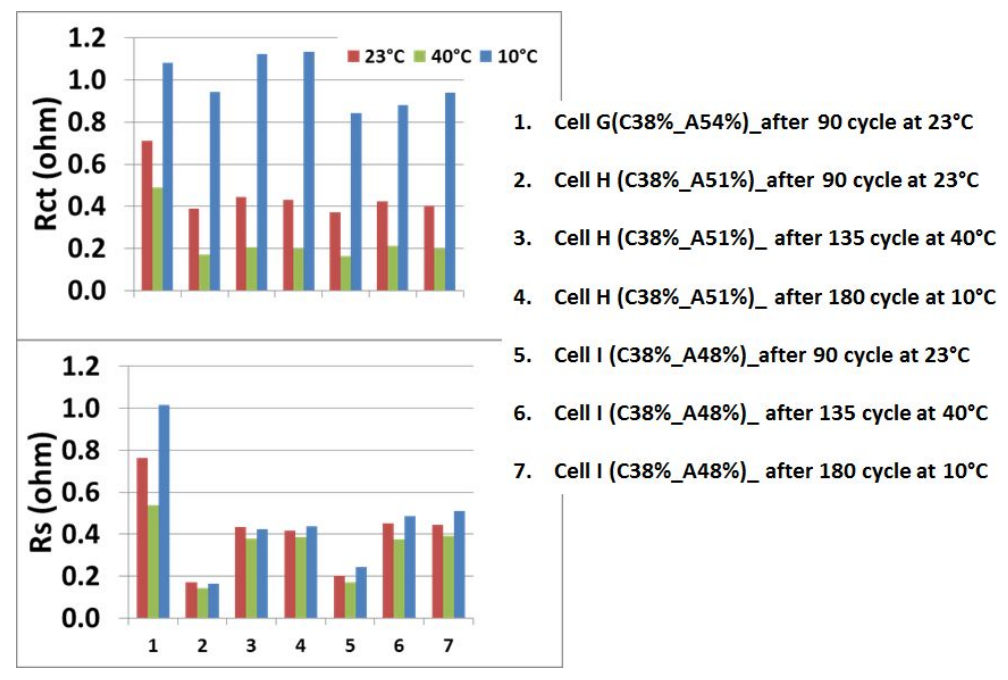

Figure 6. Comparison of the $R_{S}$ and $R_{c t}$ resistance values of the Li-ion full cells, containing electrodes with different porosities, after cycling at different temperatures.

It can be seen that Cell G (C38\%-A54\%) has a significantly higher surface and charge transfer resistances, which is possibly due to less intimate particle to particle contacts throughout the electrodes. The high frequency semicircle exhibits the impedance $\left(R_{S}\right)$ due to the formation of the passivating film (SEI) on the graphite surface, and thus, the increase in the size of the semicircle could be caused by the growth of the SEI film, which could become thicker after each cycle. The instability in the passivated layer, which consumes a portion of the intercalated lithium, decreases the overall electrochemical performance [11]. The volume change during Li intercalation-deintercalation and C-rates can affect further the stability of electrodes with high porosity $(>51 \%)$ and lead to a loss of contact among particles and electrode-substrate foils.

A gradual increase in the charge transfer resistance was observed while the surface resistance gets almost saturated upon cycling. The $R_{c t}$ is reduced at $40{ }^{\circ} \mathrm{C}$, while it increases considerably at $10^{\circ} \mathrm{C}$, which is due to the change in the ionic conductivity of the electrolyte at elevated temperatures. As temperature increases, the $R_{c t}$ decreases, which is related to the Butler-Volmer kinetic equation for the activation-controlled charge transfer electrochemical reaction [12]. Among all combinations of porosities, Cell I (C38\%-A48\%) exhibits the smallest charge transfer resistance. 
The comparison of the volumetric energy density (Wh/L) values obtained from the full cells, containing NMC cathodes with $38 \%$ porosity and graphite anodes with $48 \%, 51 \%$ and $54 \%$ porosities, at different C-rates at temperatures of $23^{\circ} \mathrm{C}, 40^{\circ} \mathrm{C}$ and $10^{\circ} \mathrm{C}$ is displayed in Figure 7 . The same full cells were cycled at different temperatures. A simple calculation was done taking the anode, cathode, separator and half of the substrate foils thicknesses into account to calculate the volume of the electrode stack and its volumetric energy density in $\mathrm{Wh} / \mathrm{L}$. The pouch foil and current tabs are not included in the calculation.

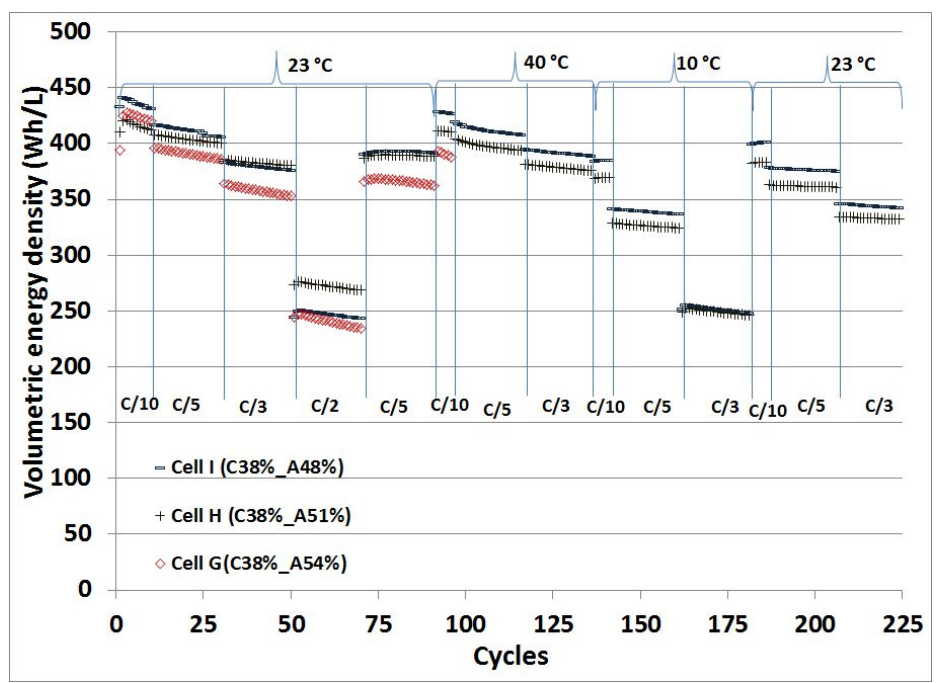

Figure 7. Comparison of the volumetric energy density $(\mathrm{Wh} / \mathrm{L})$ values obtained from the full cells, containing electrodes with different porosities, at different C-rates and different temperatures.

The volumetric energy densities of $425 \mathrm{Wh} / \mathrm{L}, 421 \mathrm{Wh} / \mathrm{L}$ and $441 \mathrm{Wh} / \mathrm{L}$ [1] are obtained from the full cells, Cell G (C38\%-A54\%), Cell H (C38\%-A51\%) and Cell I (C38\%-A48\%) at the C/10 rate, respectively. Cell G (C38\%-A54\%) shows slightly higher energy density than Cell $\mathrm{H}(\mathrm{C} 38 \%$-A $51 \%)$, but lower than Cell I (C38\%-A48\%), which might be due to negligible kinetic limitations and appropriate ionic conduction throughout the electrode due to high porosity. As the C-rate increases, a reduction in the energy density value is observed with Cell G (C38\%-A54\%). The energy density loss at a high C-rate could be mainly attributed to the graphite electrode due to the formation of the passivating layer on the surface, which consumes a portion of intercalated lithium in every cycle. The energy density values are quite satisfactory up to the $C / 3$ rate, but as expected for thick electrodes, the energy density deteriorates significantly at higher $C$-rates. After applying cycles at $C / 2$, the cells restored slightly lower energy density values after 70 cycles at $C / 5$.

After 90 cycles, Cell I (C38\%-A48\%) at $40{ }^{\circ} \mathrm{C}$ delivered volumetric energy densities of $428 \mathrm{Wh} / \mathrm{L}$, $416 \mathrm{Wh} / \mathrm{L}$ and $395 \mathrm{Wh} / \mathrm{L}$ at C/10, C/5 and C/3 rates, respectively. A 4\% reduction in the energy density was observed when the porosity is increased to $51 \%$ on the anode side. Cell G (C38\%-A54\%) has stopped working after 95 cycles. This might be due to the reconstruction of the SEI layer during the cycling at high C-rates, and that led to lithium plating at the surface of the negative electrodes. Cell I (C38\%-A48\%) at $10{ }^{\circ} \mathrm{C}$ showed a 10\%, $17 \%$ and $36 \%$ reduction in the energy density values at the same C-rates after 135 cycles in comparison to the energy density obtained at $40{ }^{\circ} \mathrm{C}$. The energy density deteriorates faster at low temperature $\left(10^{\circ} \mathrm{C}\right)$ when the $\mathrm{C}$-rate increases, while the cells showed an improvement in the energy density at a high temperature $\left(40^{\circ} \mathrm{C}\right)$. The cells showed almost the same energy density when the cells are cycled at $23{ }^{\circ} \mathrm{C}$ at the $\mathrm{C} / 2$ rate and $10{ }^{\circ} \mathrm{C}$ at $\mathrm{C} / 3$. The cells were further cycled again at $23^{\circ} \mathrm{C}$ after 180 cycles. The cells restored energy densities slightly less than the initial densities. The cells showed negligible losses in the energy density values up to $C / 5$ rates even after 180 cycles. Cell I (C38\%-A48\%) exhibits the highest energy density upon cycling at different temperatures and different $\mathrm{C}$-rates. 
From the volumetric and gravimetric energy density results, it could be concluded that porosity $\sim 38 \%$ on the cathode side and $\sim 48 \%$ on the anode side, which is quite higher in comparison to commercial electrodes, showed maximum energy density. For the thick electrodes, a $10 \%$ and a $20 \%$ reduction on the cathode and anode side of the original thickness of the dried film could provide the optimized porosity for the thick electrodes $(250-350 \mu \mathrm{m})$.

\section{Conclusions}

In this work, graphite and NMC(111) electrodes for lithium ion cells with thicknesses from $250 \mu \mathrm{m}$ to $350 \mu \mathrm{m}$ and with high porosities $(48 \%-58 \%$ for anodes and $38 \%-44 \%$ for cathodes) for enhanced lithium transport in the organic electrolyte phase were prepared and tested in full cell configuration. The mechanical integrity of the electrodes, which would be prone to disintegration at these low levels of compression, was improved by the addition of carbon fibers. Carbon fibers provide better long-range conductivity in thick electrodes in comparison to the conductivity among the particle-to-particle contact. It was shown that the cells could reach energy densities of $189 \mathrm{Wh} / \mathrm{kg}$ and $441 \mathrm{Wh} / \mathrm{L}$ at C/10 with the porosities ( $38 \%$ cathode and $48 \%-51 \%$ anode). The cell (C38\%-A48\%) exhibits the highest energy density upon cycling at elevated temperatures and different $\mathrm{C}$-rates. The cell with minimum maintained porosities (C38\%-A48\%) showed the lowest potential drop and better electrochemical performance as the electrodes have a better electronic and ionic network. The particle to particle contact improve upon calendering, which provided a continuous network within the electrode layers from the upper surface to the lower surface. It was observed that the porosity $>50 \%$ on the anode side and that $>40 \%$ on the cathode side do not enhance the electrochemical performance of the cell.

Acknowledgments: The authors thank the Karlsruhe Institute of Technology (KIT) and the Helmholtz Institute Ulm (HIU) for financial support.

Author Contributions: Horst Hahn provided the research plateform including the materials and analysis tools. Madhav Singh performed the experiments. Madhav Singh and Jörg Kaiser alalyzed the data.

Conflicts of Interest: The authors declare no conflict of interest.

\section{References}

1. Singh, M.; Kaiser, J.; Hahn, H. Thick electrodes for high energy lithium ion batteries. J. Electrochem. Soc. 2015, 162, A1196-A1201.

2. Feng, Y.; Mcguire, G.E.; Shenderova, O.A.; Ke, H.; Burkett, S.L. Fabrication of copper/carbon nanotube composite thin films by periodic pulse reverse electroplating using nanodiamond as a dispersing agent. Thin Solid Films 2016, 615, 116-121.

3. Jordan, M.B.; Feng, Y.; Burkett, S.L. Development of seed layer for electrodeposition of copper on carbon nanotube bundles. J. Vac. Sci. Technol. B 2015, 33, 021202.

4. Ahn, S.H.; Chung, G.C.; Lim, M.R.; Jun, S.H.; Bae, J.S.; Kwak, M.S. Lithium ion Secondary Battery and Manufacturing Method of the Same. U.S. Patent 20020168574, 14 November 2002.

5. Nishimura, K.; Sudo, A.; Murakami, M.; Shirane, K. Carbon Fiber Material and Electrode Material for Batteries. U.S. Patent 6,528,211, 4 March 2003.

6. Newman, J. Optimization of porosity and thickness of a battery electrode by means of a reaction-zone model. J. Electrochem. Soc. 1995, 142, 97-101.

7. Vu, A.; Qian, Y.; Stein, A. Porous electrode materials for lithium-ion batteries $\tilde{n}$ how to prepare them and what makes them special. Adv. Energy Mater. 2012, 2, 1056-1085.

8. DuBeshter, T.; Sinha, P.K.; Sakars, A.; Fly, G.W.; Jornea, J. Measurement of tortuosity and porosity of porous battery electrodes. J. Electrochem. Soc. 2014, 161, A599-A605.

9. Song, J.Y.; Lee, H.H.; Wang, Y.Y.; Wan, C.C. Two- and three-electrode impedance spectroscopy of lithium-ion batteries. J. Power Sources 2002, 111, 255-267.

10. Choi, Y.-M.; Pyun, S.-I. Effects of intercalation-induced stress on lithium transport through porous $\mathrm{LiCoO}_{2}$ electrode. Solid State Ion. 1997, 99, 173-183. 
11. Dolle, M.; Orsini, F.; Gozdz, A.S.; Tarascon, J.-M. Development of reliable three-electrode impedance measurements in plastic Li-ion batteries. J. Electrochem. Soc. 2001, 148, A851-A857.

12. Gomez, J.; Nelson, R.; Kalu, E.E.; Weatherspoon, M.H.; Zheng, J.P. Equivalent circuit model parameters of a high-power Li-ion battery: Thermal and state of charge effects. J. Power Sources 2011, 196, 4826-4831.

(c) 2016 by the authors; licensee MDPI, Basel, Switzerland. This article is an open access article distributed under the terms and conditions of the Creative Commons Attribution (CC-BY) license (http://creativecommons.org/licenses/by/4.0/). 